\title{
CRYOVOLCANISM ON THE ICY SATELLITES
}

\author{
J.S. KARGEL \\ U.S. Geological Survey \\ 2255 N. Gemini Dr., Flagstaff, AZ 86001
}

\begin{abstract}
Evidence of past cryovolcanism is widespread and extremely varied on the icy satellites. Some cryovolcanic landscapes, notably on Triton, are similar to many silicate volcanic terrains, including what appear to be volcanic rifts, calderas and solidified lava lakes, flow fields, breached cinder cones or stratovolcanoes, viscous lava domes, and sinuous rilles. Most other satellites have terrains that are different in the important respect that no obvious volcanoes are present. The preserved record of cryovolcanism generally is believed to have formed by eruptions of aqueous solutions and slurries. Even Triton's volcanic crust, which is covered by nitrogen-rich frost, is probably dominated by water ice. Nonpolar and weakly polar molecular liquids (mainly $\mathrm{N}_{2}, \mathrm{CH}_{4}, \mathrm{CO}, \mathrm{CO}_{2}$, and Ar), may originate by decomposition of gas-clathrate hydrates and may have been erupted on some icy satellites, but without water these substances do not form rigid solids that are stable against sublimation or melting over geologic time. Triton's plumes, active at the time of Voyager 2's flyby, may consist of multicomponent nonpolar gas mixtures. The plumes may be volcanogenic fumaroles or geyserlike emissions powered by deep internal heating, and, thus, the plumes may be indicating an interior that is still cryomagmatically active; or Triton's plumes may be powered by solar heating of translucent ices very near the surface. The Uranian and Neptunian satellites Miranda, Ariel, and Triton have flow deposits that are hundreds to thousands of meters thick (implying highly viscous lavas); by contrast, the Jovian and Saturnian satellites generally have plains-forming deposits composed of relatively thin flows whose thicknesses have not been resolved in Voyager images (thus implying relatively lowviscosity lavas). One possible explanation for this inferred rheological distinction involves a difference in volatile composition of the Uranian and Neptunian satellites on one hand and of the Jovian and Saturnian satellites on the other hand. Perhaps the Jovian and Saturnian satellites tend to have relatively "clean" compositions with water ice as the main volatile (ammonia and water-soluble salts may also be present). The Uranian and Neptunian satellites may possess large amounts of a chemically unequilibrated comet-like volatile assemblage, including methanol, formaldehyde, and a host of other highly water- and ammonia-water-soluble constituents and gas clathrate hydrates. These two volatile mixtures would produce melts that differ enormously in viscosity The geomorphologic similarity in the products of volcanism on Earth and Triton may arise partly from a rheological similarity of the ammonia-water-methanol series of liquids and the silicate series ranging from basalt to dacite. An abundance of gas clathrate hydrates hypothesized to be contained by the satellites of Uranus and Neptune could contribute to evidence of explosive volcanism on those objects.
\end{abstract}




\section{Introduction}

In six planetary flybys during the period from 1979-1989 the two Voyager spacecraft unveiled the surfaces of numerous satellites of the four largest planets in the solar system. Voyager images showed for the first time details of the ice-covered surfaces and the dynamic geologic histories of many of these objects (Smith et al., 1979, 1982, 1986, 1989). The surfaces of the icy satellites present almost as great a range of geologic phenomena as presented by the rocky planets (Rothery 1992), though we know much less about the former than the latter. The basic properties of icy satellites are quite varied (Burns 1986). Their unique surface expressions apparently reflect individualized geologic evolutionary histories that, in turn, relate to some very large differences in factors such as thermal evolution, composition, interior pressure, surface temperature, surface gravity, and impact history.

None of the very small, irregularly shaped icy satellites of the outer solar system (such as Proteus and Hyperion and other satellites with mean radii less than $\sim 200 \mathrm{~km}$ ) have any indication of resurfacing except by the impacts that formed them as fragments of once-larger objects (Thomas 1989, Farinella et al. 1990, Croft 1992). Some major ellispoidally shaped icy satellites, notably Mimas, Rhea, and Callisto, also lack compelling evidence of volcanic resurfacing; instead, they have intensely cratered surfaces everywhere that the Voyager spacecraft looked (Smith et al., 1979, 1982). In a dramatic confirmation of pre-Voyager predictions that large icy satellites should be differentiated (Lewis 1971, Consolmagno and Lewis 1978), the Voyager project found that some of the most interesting geologic processes on many icy satellites involved cryovolcanism (i.e., the eruption of icy-cold aqueous or nonpolar molecular solutions or partly crystallized slurries, derived by partial melting of ice-bearing materials) (Smith et al., 1979, 1982, 1986, 1989). What was not predicted was the discovery of active cryovolcanism or gas venting on Triton and evidence of past cryovolcanism on objects as small as Enceladus and Miranda (with radii of 249 and $242 \mathrm{~km}$, respectively). Several active, surface-vented plumes were indeed observed on Triton during the last of the Voyager satellite encounters (Smith et al. 1989, Kirk et al. 1995). Other satellites, notably Enceladus and Europa, have strong geologic evidence of geologically recent and possibly (but not necessarily) active volcanic resurfacing (Smith et al. 1979, 1982; Lucchitta and Soderblom 1982; Squyres et al. 1983). Many other icy satellites, notably Ganymede, Tethys, Dione, Miranda, and Ariel, have abundant evidence of ancient cryovolcanic resurfacing, but virtually no evidence for ongoing or geologically very recent activity (Smith $e$ t al. 1979, 1982, 1986; Shoemaker $e t$ al. 1982; Croft and Soderblom 1991).

Unfortunately, very little is known of the exact fluids that were responsible for the genesis of the varied cryovolcanic landscapes. Indirect evidence suggests that the lavas were fundamentally aqueous liquids or partly crystallized aqueous slurries in most instances, though they may have had considerable chemical variability (Stevenson 1982; Squyres et al. 1983; Smith et al., 1989, Kargel and Strom 1990, Croft and Soderblom 1991; Kargel 1991, 1992; Kargel et al. 1991; Schenk 1991), and some of these "lavas" possibly may even have included eruptions of water mainly in the solid state (Jankowski and Squyres 1988). The exact compositions of the liquids generated by partial melting in the interiors of icy satellites depends on the composition of the ices and of the water-soluble material in the rocky fraction. Until we obtain actual samples of icy satellites, our knowledge of their compositions is underconstrained by a few critical observations and theoretical calculations. 


\section{Cryovolcanic landforms and landscapes}

The resolution of the best Voyager images of icy satellites was commonly sufficient to resolve features at a scale of 1-2 km, good enough to identify volcanic terrains but generally not good enough to resolve details of individual flow units unless they are of very great thickness (as they are on Miranda, Ariel, and Triton). Under favorable conditions of imaging and illumination, for instance near the terminator, tectonic scarps and crater rims on Ganymede and Enceladus that are $\sim 100 \mathrm{~m}$ high are readily visible in Voyager images, yet good examples of flows of comparable (or greater) thickness were not found on either object (or on any other satellite in the Jovian and Saturnian systems). The extrusional origin of cryovolcanic plains on Ganymede and Enceladus was recognized by the similarity of their appearance and stratigraphic relations to plains of known volcanic origin-- the lunar maria, for instance, consist of smooth deposits of basaltic lava that (1) occupy low-lying regions, (2) embay or partly bury large impact craters and other types of adjoining rugged highlands, and (3) apparently completely bury large numbers of small impact craters (inferred from crater size-frequency statistics; Strom 1986). These relations are visible in images of the lunar maria at resolutions comparable to those produced by Voyager, but individual lava flows are not recognizable. Some of the plains on Ganymede can be traced to specific fracture zones, which probably served as eruption conduits from which vast sheets or lakes of water or aqueous solutions apparently were erupted. Hence, there is little doubt that the smooth resurfaced plains on many icy satellites are actually of extrusional origin.

At the simplest level of interpretation, effusive cryovolcanic deposits come in two types: (1) plains-forming flows of unresolved relief occur on several Jovian and Saturnian satellites, including Europa (Fig. 1), Ganymede (Fig. 2), Enceladus (Fig. 3), Tethys, and Dione, as well as Neptune's satellite, Triton; and (2) thick, lobate flow units (hundreds to a couple thousand meters thick), large volcanic constructs, and volcanic channels occur on the Uranian and Neptunian satellites, including Miranda (Fig. 4), Ariel (Fig. 5), and Triton (Figs. 6-8).

Some of the most interesting cryovolcanic features are those where individual flow units and other discrete volcanic landforms can be resolved, especially the volcanic features of Triton, which has cryovolcanic landscapes that are most astonishing for their similarity to volcanic terrains on Earth and the other rocky bodies (Kargel and Strom 1990, Croft et al. 1995). Triton has features that are morphologically similar to volcanic calderas and associated flow fields on Venus, Earth, Mars, and Io; rhyolite and dacite flows and domes on Earth; cinder cones and other cratered volcanic cones on Venus and Earth; rift-controlled crater chains on Venus, Earth, and Mars; and craterheaded sinuous rilles or collapsed lava tubes on Venus, Earth, Moon, and Mars. This similarity seems to require cryolavas on Triton that behaved volcanologically much as silicate lavas behave on the terrestrial planets.

Evidence for explosive cryovolcanism is widespread on some icy satellites, especially on Triton (also possibly on Enceladus and Miranda), but absent on other satellites (notably Europa and Ganymede). Triton has cratered cones that resemble breached cinder cones and composite stratovolcanoes (such as Mount Saint Helens) on Earth. Each of Triton's large smooth-floored walled planitia (caldera or lava lake analogs) has a central hummocky and pitted region that may have been the site of latestage cryoclastic eruptive activity. Elsewhere on Triton, a mantling deposit tapers to a feather edge, suggesting that this terrain is overlain by a cryoclastic blanket analogous to terrestrial ignimbrite sheets. 


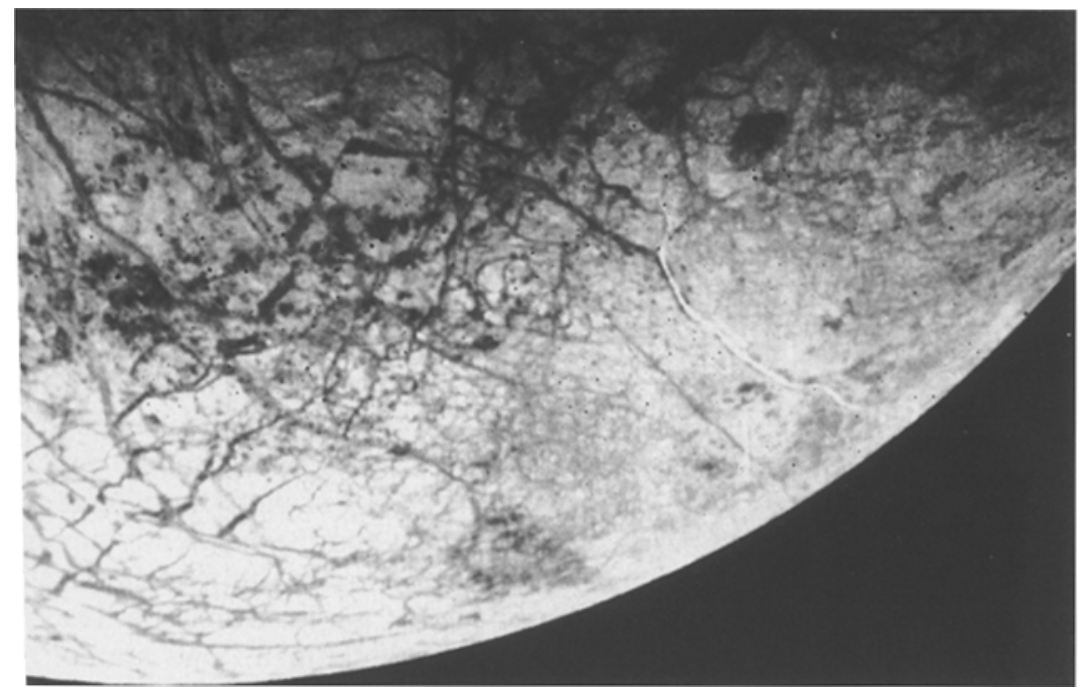

Figure 1. Voyager image 20649.25, showing a smooth but highly fractured surface of Europa. This scene has been likened to sea ice, and it suggests complete flooding and tectonic disruption of the surface. Scene $\sim 1600 \mathrm{~km}$ tleft to right .

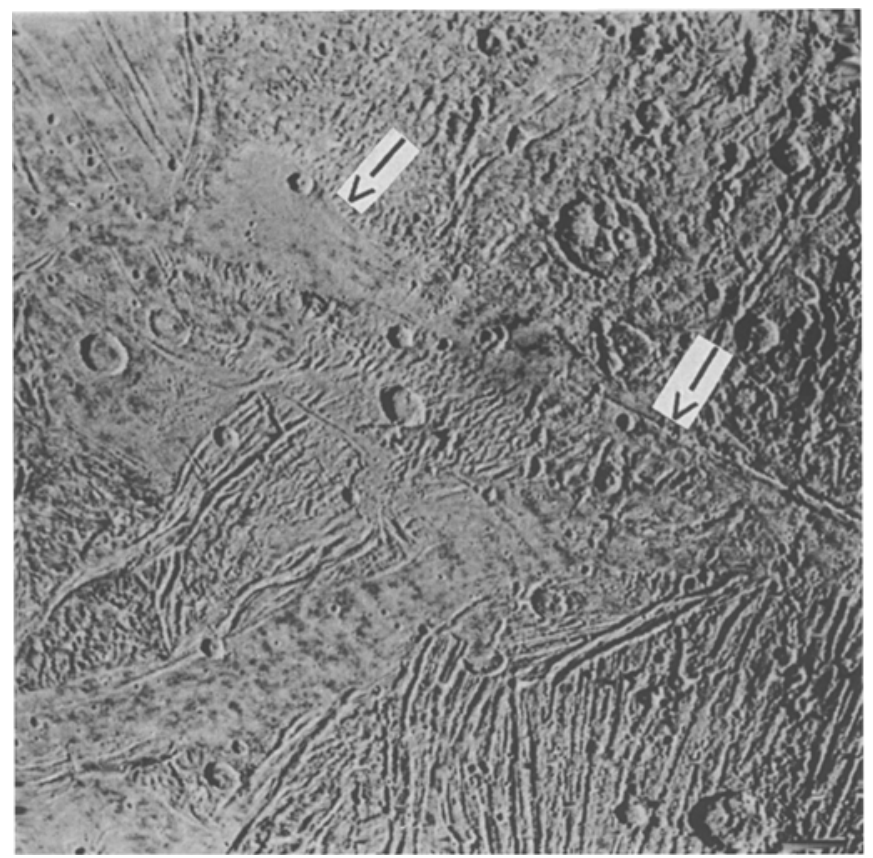

Figure 2. Voyager image 20640.25, showing a typical region of Ganymede's young, lightly cratered grooved terrain and remnants of an older cratered terrain. Groove sets are locally completely flooded by smooth plains composed of cryovolcanic deposits of higher albedo than the cratered terrain (albedo differences are suppressed in this processed version of the image). The smooth terrain in the upper left quadrant (arrow) appears to have been extruded from a prominent fracture zone visible at right center (arrow). Scene $\sim 850 \mathrm{~km}$ across. 


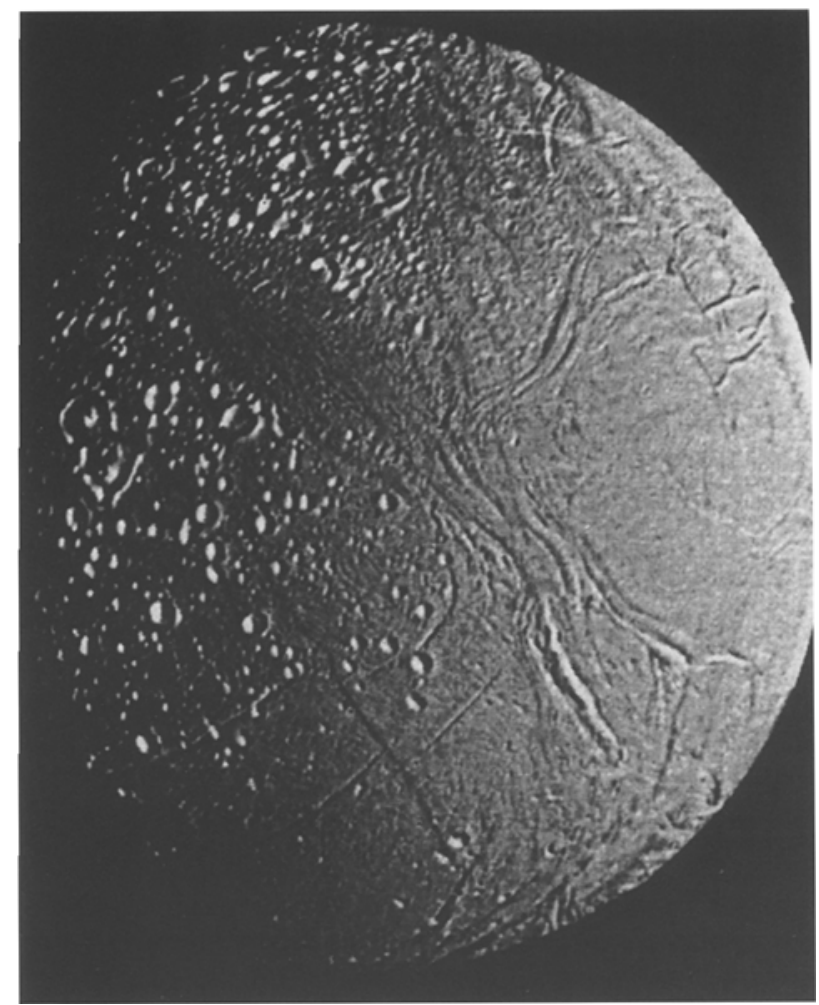

Figure 3. Global view of Enceladus (diameter $500 \mathrm{~km}$ ). Sinuous mountain ridges, over $1 \mathrm{~km}$ high in places, and fracture belts cut areas of lightly to heavily cratered plains. Smooth plains appear to be cryovolcanic.

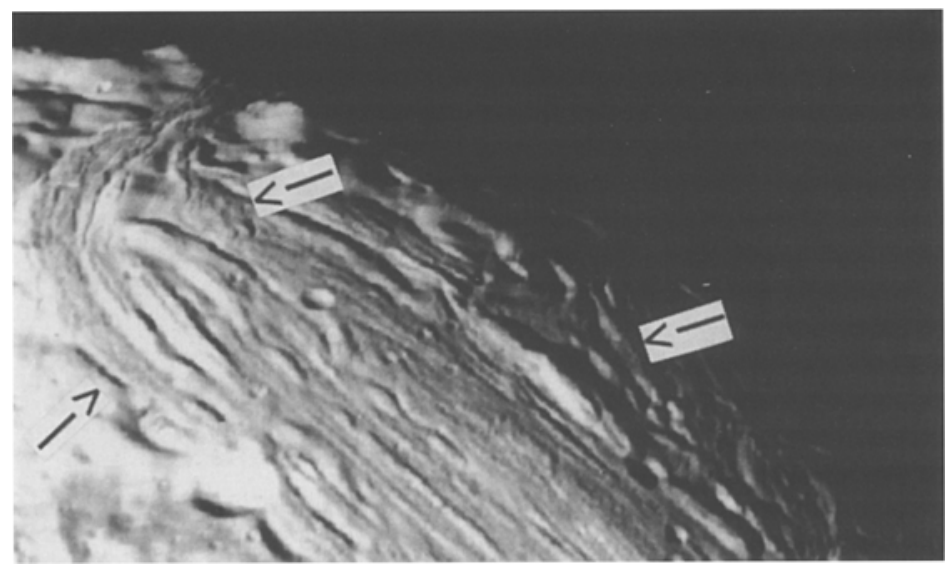

Figure 4. Image showing cryovolcanic plains in part of Elsinore Corona, Miranda, apparently including highly viscous effusive deposits (arrows). Scene $\sim 90 \mathrm{~km}$ across. 


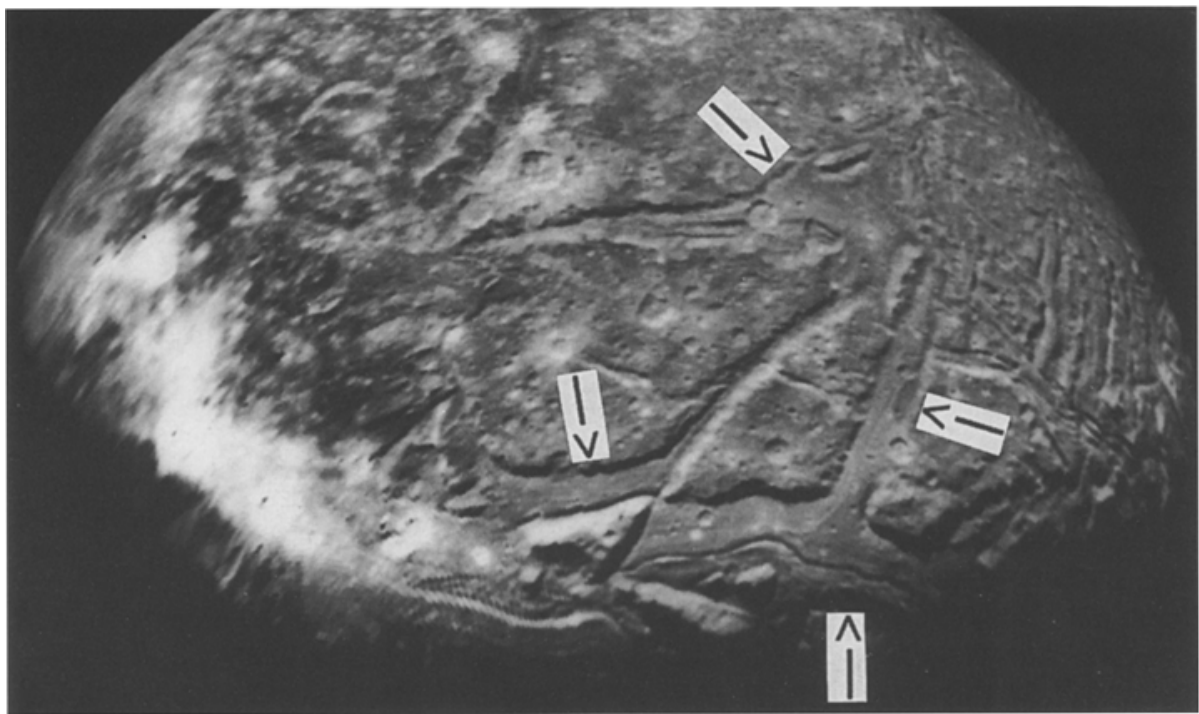

Figure 5. Image showing a complex system of canyons and one of several prominent, viscous flows on Ariel, some of which are over $1 \mathrm{~km}$ thick. The largest flows occur on the troughs' floors (arrows).

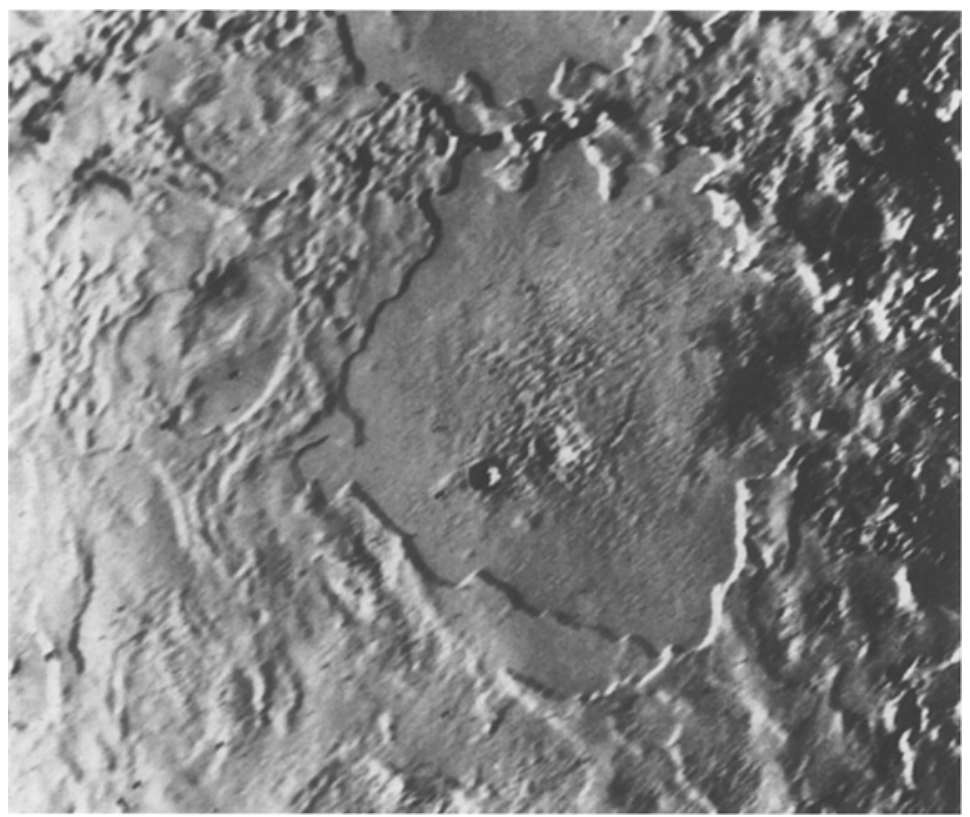

Figure 6. Ruach Planitia, Triton, and vicinity. The planitia is about $200 \mathrm{~km}$ across, and includes a scalloped wall $-200 \mathrm{~m}$ high, an inner terrace, a mostly smooth floor, an central area of complex pits and hummocks, and a sinuous rille. This feature resembles volcanic calderas and lava lakes on Earth, Venus, Mars, and lo. The region outside and to the left of the planitia appears to consist of multiple flows that spilled from Ruach Planitia and neighboring Tuonela Planitia, part of which is visible at the top of the image. 


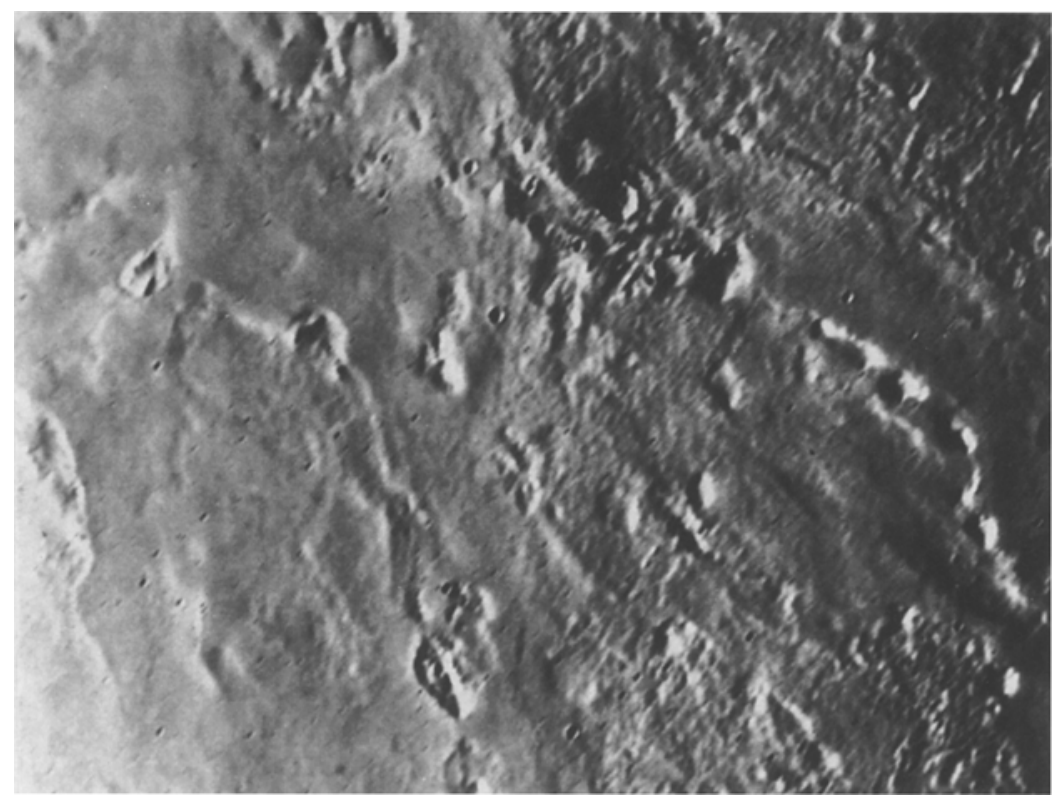

Figure 7. Cipango Planum, Triton. This area may be the distal region of flows spilled from Ruach and Tuonela Planitiae. A probable thick flow margin, left of center, appears to have wrapped around a protruding hill. Right of center is a volcanic rift, along which several volcanic craters are aligned and from which smooth deposits appear to have issued. Just below and left of center is an elongate volcanic crater containing what appears to be a viscous domical effusion. Scene roughly $300 \mathrm{~km}$ across.

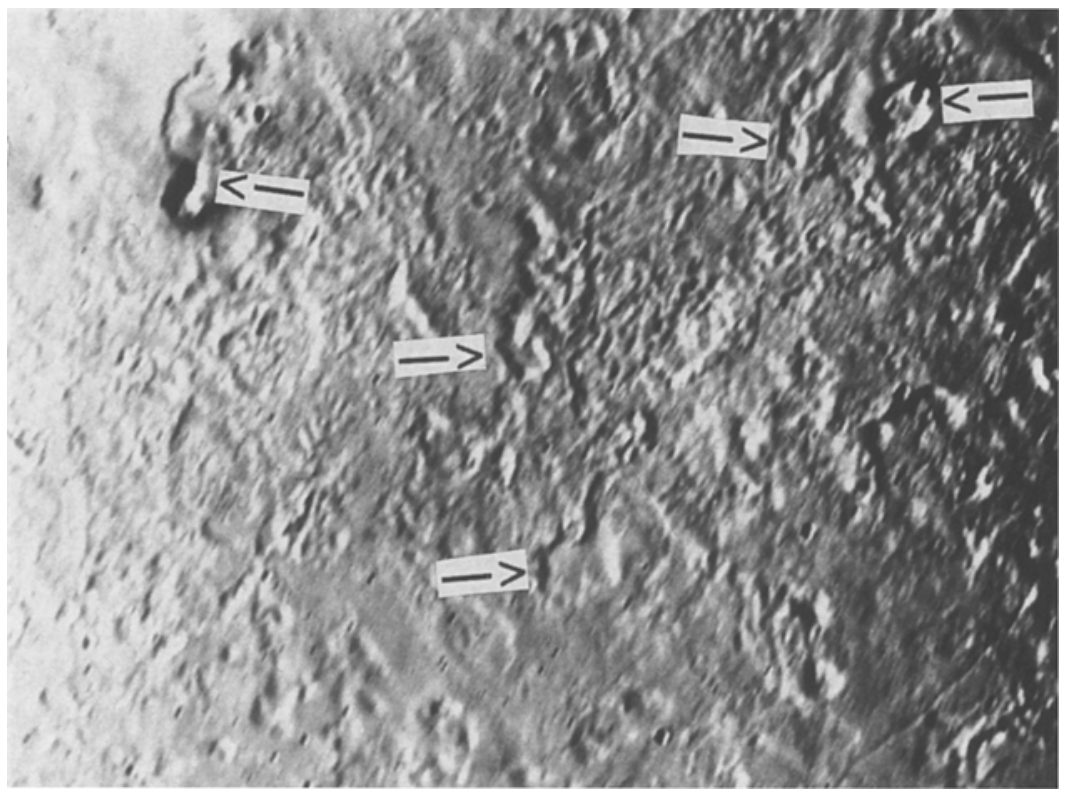

Figure 8. Area of southern Monad Regio, Triton, showing several volcanic craters and possible sinuous rilles oriented consistently from volcanic craters (arrows) toward the top of the image. 


\section{Properties and compositions of icy satellites}

Remote reflectance spectroscopy has yielded a reasonably good knowledge of the major icy mineralogic components in the visible surface layers of all major icy satellites, a rough idea of the fraction and possible composition of nonice (rocky) components in this layer, and clues to the possible presence of certain minor components (e.g., Clark et al. 1986). Almost all icy satellites have surfaces that are dominated by the spectral reflectance of water ice; the ice generally is intermixed with variable quantities of nonice components of low visual albedo and spectrally gray, yellowish, or reddish coloration. The nonice components may include rocky material and the photolysis products of carbonaceous ices. There are exceptions to these generalizations; Triton has a surface dominated by $\mathrm{N}_{2}$ and other nonpolar molecules, and Enceladus' surface contains virtually none of the low-albedo components. In all cases, these data apply only to the visible surface microlayer. This layer may be nonrepresentative of the satellite as a whole or even of the material a meter below the surface because of the effects of igneous and gravitational differentiation and chemical processing in the space environment (especially electromagnetic and charged particle radiation).

Two other approaches to the possible compositions of icy satellites, summarized in Table 1, are based on (1) theoretical modeling of low-temperature nebular condensation of rocky and icy phases (e.g., Lewis 1972, Prinn and Fegley 1988), and (2) observations of the compositions of comets and certain meteorites, which may represent the building blocks of some icy satellites. Cometary volatiles are particularly probable constituents of the satellites of Uranus and Neptune, because it is thought that comets mainly had their origins in the solar nebula near the orbits and Uranus and Neptune. Six model compositions are listed in Table 1 and show some of the possible variety of volatile assemblages and the types of liquids that could be generated from them. Some distinctive properties and possible volcanological behavior of a few of these liquids are summarized in Table 2. The predicted cryovolcanic liquids are of two general types-- aqueous solutions and non-polar molecular solutions. The possible planetary applications of these various lava types (Table 2) are highly speculative, but this listing highlights the probable chemical variety of cryovolcanism.

Pre-Voyager thermal models suggested that aqueous igneous differentiation may have been driven by radiogenic heating in icy satellites as small as $500 \mathrm{~km}$ in radius (Lewis 1971, Consolmagno and Lewis 1978). Besides the discovery that cryovolcanism affected satellites of half the minimum predicted size, it was unanticipated that the geomorphic expression of cryovolcanism could vary so tremendously from one object to another.

The small sizes of some partly melted satellites has been explained by (1) the highly efficient generation of heat in special cases by tidal dissipation (in addition to radiogenic and accretional heating; Ellsworth and Schubert 1983, Squyres et al. 1988), (2) a reduction in the melting point of multicomponent volatile assemblages relative to the melting point of pure ice (e.g., ice m.p. $273 \mathrm{~K}$, ammonia dihydrate m.p. $176 \mathrm{~K}$, ammonia-water-methanol m.p. $\sim 153 \mathrm{~K}$ ), and (3) conductive heat loss reduced by the insulating effects of substances of very low thermal conductivity (e.g., gas clathrate hydrates and porous megaregoliths). The geomorphic variety of cryovolcanism is partly explained by differences in the composition of the volatile-rich assemblages that constitute icy satellites (hence, differences in the composition and physical properties of partial melts). The possible importance of ammonia in lowering the melting point of ice (thereby making melting easier to accomplish on a small energy budget) was 
TABLE 1. Some volatile condensate assemblages and their partial meits

Assemblage in rough order (to right) of decreasing temperature and degree of low-temperature chemical equilibration

\begin{tabular}{|c|c|c|c|c|c|c|}
\hline Molecule & $\begin{array}{l}\text { CI- or CM- } \\
\text { chondrites + } \\
\text { water ice, } \\
T_{\text {cond }}=160 \mathrm{~K}\end{array}$ & $\begin{array}{l}\mathrm{NH}_{3}-\mathrm{CH}_{4}- \\
\text { rich nebula, } \\
\text { homogeneous } \\
\text { accretion near } \\
T_{\text {cond }}=100 \mathrm{~K} \\
\text { (Lewis } 1972 \text { ) }\end{array}$ & $\begin{array}{l}\mathrm{NH}_{3}-\mathrm{CH}_{4}- \\
\text { rich nebula, } \\
\text { homogeneous } \\
\text { accretion near } \\
\mathrm{T}_{\text {cond }}=40 \mathrm{~K} \\
\text { (Lewis } 1972 \text { ) }\end{array}$ & $\begin{array}{l}\mathrm{NH}_{3}-\mathrm{CH}_{4}- \\
\text { rich nebula, } \\
\text { heterogeneous } \\
\text { accretion near } \\
\mathrm{T}_{\text {cond }}=40 \mathrm{~K} \\
\text { (Lewis } 1972 \text { ) }\end{array}$ & $\begin{array}{l}\mathrm{CO}-\mathrm{N}_{2}- \\
\text { rich nebula, } \\
\mathrm{T}_{\text {cond }}=40 \mathrm{~K} \\
\text { (Prinn and } \\
\text { Fegley } 1988 \text { ) }\end{array}$ & Comets \\
\hline $\mathrm{H}_{2} \mathrm{O}$ & 100 & 100 & 100 & 100 & 100 & 100 \\
\hline $\mathrm{MgSO}_{4}$ & $0.5-2.5$ & 0 & 0 & 0 & 0 & 0 \\
\hline $\mathrm{NH}_{3}$ & 0 & 12 & $12^{1}$ & $12^{3}$ & 0.01 & $0.1-2.0$ \\
\hline $\mathrm{CH}_{4}$ & 0 & 0 & $60^{2}$ & $60^{4}$ & $<12$ & $0.7+2$ \\
\hline $\mathrm{H}_{2} \mathrm{~S}$ & 0 & 0 & 0 & $2.6^{5}$ & & \\
\hline $\mathrm{CO}$ & 0 & 0 & 0 & 0 & 100 & $1-7$ \\
\hline $\mathrm{CO}_{2}$ & 0 & 0 & 0 & 0 & 1 & $1.5-3.5$ \\
\hline $\mathrm{HCN}$ & 0 & 0 & 0.01 & 0 & & $0.1-0.3$ \\
\hline $\mathrm{CH}_{3} \mathrm{OH}$ & 0 & 0 & 0 & 0 & & $0.1-10$ \\
\hline $\mathrm{H}_{2} \mathrm{CO}$ & 0 & 0 & 0 & 0 & & $1-10$ \\
\hline$N_{2}$ & 0 & 0 & 0 & 0 & 12 & $1-10$ \\
\hline $\begin{array}{l}\text { Possible compo- } \\
\text { sitions of partial } \\
\text { melts (melting } \\
\text { temperature in- } \\
\text { creases down- } \\
\text { ward in list) }\end{array}$ & $\begin{array}{l}\text { a. } \mathrm{H}_{2} \mathrm{O}-\mathrm{MgSO} \mathrm{SO}_{4} \\
\text { b. } \mathrm{H}_{2} \mathrm{O}\end{array}$ & $\begin{array}{l}\text { a. } \mathrm{H}_{2} \mathrm{O}-\mathrm{NH}_{3} \\
\text { b. } \mathrm{H}_{2} \mathrm{O}\end{array}$ & $\begin{array}{l}\text { a. } \mathrm{CH}_{4} \\
\text { b. } \mathrm{H}_{2} \mathrm{O}-\mathrm{NH}_{3}- \\
\mathrm{CH}_{4} \\
\text { c. } \mathrm{CH}_{4} \text { and } \\
\mathrm{H}_{2} \mathrm{O}-\mathrm{CH}_{4} \\
\text { d. } \mathrm{H}_{2} \mathrm{O}\end{array}$ & $\begin{array}{l}\text { a. } \mathrm{CH}_{4} \\
\text { b. } \mathrm{H}_{2} \mathrm{O}-\mathrm{NH}_{3}- \\
\left(\mathrm{NH}_{4}\right)_{2} \mathrm{~S}- \\
\mathrm{CH}_{4} \\
\text { c. } \mathrm{NH}_{3}-\mathrm{H}_{2} \mathrm{O}- \\
\left(\mathrm{NH}_{4}\right)_{2} \mathrm{~S}-\mathrm{CH}_{4} \\
\text { d. } \mathrm{CH}_{4} \text { and } \\
\mathrm{H}_{2} \mathrm{O}-\mathrm{CH}_{4} \\
\text { e. } \mathrm{H}_{2} \mathrm{O}\end{array}$ & $\begin{array}{l}\text { a. } \mathrm{N}_{2} \\
\text { b. } \mathrm{CO}-\mathrm{CH}_{4}- \\
\mathrm{N}_{2}-\mathrm{CO}_{2} \\
\text { c. } \mathrm{H}_{2} \mathrm{O}-\mathrm{CO}_{2-} \\
\mathrm{CH}_{4-}-\mathrm{N}_{2-} \\
\quad \mathrm{CO} \\
\text { d. } \mathrm{H}_{2} \mathrm{O}\end{array}$ & $\begin{array}{l}\text { a. } \mathrm{N}_{2} \\
\text { b. } \mathrm{N}_{2}-\mathrm{CO}- \\
\mathrm{CH}_{4-} \\
\mathrm{CO}_{2} \\
\text { c. } \mathrm{H}_{2} \mathrm{O}- \\
\mathrm{CH}_{3} \mathrm{OH} \\
\text { d. } \mathrm{H}_{2} \mathrm{O}\end{array}$ \\
\hline
\end{tabular}

$T_{\text {cond }}$ is the condensation temperature.

1 Other water-soluble salts, especially $\mathrm{Na}_{2} \mathrm{SO}_{4}$, are also abundant in $\mathrm{CI}$ and $\mathrm{CM}$ carbonaceous chondrites and should constirute significant potential solutes in cryovolcanic brines. Some of these salts or their reaction products with ammonia (e.g., $\left(\mathrm{NH}_{4}\right)_{2} \mathrm{SO}_{4}$ ) may also occur in melts produced in the other low-temperature condensate assemblages.

2 Partly as clathrate hydrate, excess as pure methane ice.

3 Partly as sulfide.

4 As pure methane ice.

5 As ammonium sulfide.

recognized prior to Voyager. It was not until fairly late in the Voyager mission that the possible importance of ammonia and other volatiles besides water was recognized with regard to (1) other physical properties of cryovolcanic liquids, such as viscosity, density, and vapor pressure, and (2) cryovolcanic landform development. The Voyager 2 Uranus encounter and then the Neptune/Triton flyby revealed types of cryovolcanic features, especially thick effusive flows and numerous features formed by explosive 
TABLE 2. Properties of selected candidate cryomagmas (eutectoid compositions)

\begin{tabular}{|c|c|c|c|c|c|c|c|}
\hline Liquid & $\begin{array}{l}\text { Liquid com- } \\
\text { position, } \\
\text { mass \% }\end{array}$ & $\begin{array}{l}\text { Melting } \\
\text { point, } \mathrm{K}\end{array}$ & $\begin{array}{l}\text { Liquid } \\
\text { density, } \\
\mathrm{g} \mathrm{cm}^{-3}\end{array}$ & $\begin{array}{l}\text { Viscosity } \\
\text { of liquid, } \\
\text { poises }\end{array}$ & $\begin{array}{l}\text { Solid com- } \\
\text { position, } \\
\text { mass \% }\end{array}$ & $\begin{array}{l}\text { Solid } \\
\text { density, } \\
\mathrm{g} \mathrm{cm}^{-3}\end{array}$ & $\begin{array}{l}\text { Some possible } \\
\text { planetary } \\
\text { appplications }\end{array}$ \\
\hline Water & $\mathrm{H}_{2} \mathrm{O} 100 \%$ & 273 & 1.000 & 0.017 & Ice $100 \%$ & 0.917 & $\begin{array}{l}\text { Plains volcanism } \\
\text { on Europa and } \\
\text { Ganymede }\end{array}$ \\
\hline Brine & $\begin{array}{l}\mathrm{H}_{2} \mathrm{O} 81.2 \% \\
\mathrm{MgSO}_{4} 16 \% \\
\mathrm{Na}_{2} \mathrm{SO}_{4} 2.8 \%\end{array}$ & 268 & 1.19 & 0.07 & $\begin{array}{l}\text { Ice } 50 \% \\
\mathrm{MgSO}_{4} .12 \mathrm{H}_{2} \mathrm{O} 44 \% \\
\mathrm{Na}_{2} \mathrm{SO}_{4} .10 \mathrm{H}_{2} \mathrm{O} 6 \%\end{array}$ & 1.13 & $\begin{array}{l}\text { Plains volcanism } \\
\text { on Europa and } \\
\text { Ganymede }\end{array}$ \\
\hline $\begin{array}{l}\text { Ammonia- } \\
\text { water }\end{array}$ & $\begin{array}{l}\mathrm{H}_{2} \mathrm{O} 67.4 \% \\
\mathrm{NH}_{3} 32.6 \%\end{array}$ & 176 & 0.946 & 40 & $\begin{array}{l}\mathrm{NH}_{3} \cdot 2 \mathrm{H}_{2} \mathrm{O} 97 \% \\
\mathrm{NH}_{3} \cdot 1 \mathrm{H}_{2} \mathrm{O} 3 \%\end{array}$ & 0.962 & $\begin{array}{l}\text { Plains volcanism } \\
\text { on Dione, Tethys, } \\
\text { and Enceladus }\end{array}$ \\
\hline $\begin{array}{l}\text { Ammonia- } \\
\text { water-non- } \\
\text { polar gas }\end{array}$ & $\begin{array}{l}\mathrm{H}_{2} \mathrm{O} 67 \% \\
\mathrm{NH}_{3} 33 \% \\
\mathrm{CH}_{4} 0.1-2 \%\end{array}$ & 176 & 0.94 & 40 & $\begin{array}{l}\mathrm{NH}_{3} .2 \mathrm{H}_{2} \mathrm{O} 97 \% \\
\mathrm{NH}_{3} .1 \mathrm{H}_{2} \mathrm{O} 3 \%\end{array}$ & 0.96 & $\begin{array}{l}\text { Explosive vol- } \\
\text { canism and cinder } \\
\text { cones on Triton }\end{array}$ \\
\hline $\begin{array}{l}\text { Ammonia- } \\
\text { water- } \\
\text { methanol }\end{array}$ & $\begin{array}{l}\mathrm{H}_{2} \mathrm{O} \sim 47 \% \\
\mathrm{NH}_{3} \sim 23 \% \\
\mathrm{CH}_{3} \mathrm{OH} \sim 30 \%\end{array}$ & -153 & $\sim 0.978$ & $-40,000$ & $\begin{array}{l}\mathrm{NH}_{3} .1 \mathrm{H}_{2} \mathrm{O} \sim 46 \% \\
\mathrm{CH}_{3} \mathrm{OH} .1 \mathrm{H}_{2} \mathrm{O} \sim 54 \%\end{array}$ & & $\begin{array}{l}\text { Thick flows on } \\
\text { Triton, Ariel, and } \\
\text { Miranda }\end{array}$ \\
\hline $\begin{array}{l}\text { Nitrogen- } \\
\text { methane }\end{array}$ & $\begin{array}{l}\mathrm{N}_{2} 86.5 \% \\
\mathrm{CH}_{4} 13.5 \%\end{array}$ & 62 & 0.783 & 0.003 & $\begin{array}{l}100 \% \mathrm{~N}_{2}-\mathrm{CH}_{4} \\
\text { solid sol'n @ } 62 \mathrm{~K} ; \\
88 \% \mathrm{~N}_{2}-\mathrm{CH}_{4}+ \\
12 \% \mathrm{CH}_{4}-\mathrm{N}_{2} @ 38 \mathrm{~K}\end{array}$ & & $\begin{array}{l}\text { Sapping fluid, } \\
\text { sublimable lava, } \\
\text { and "geyser" gas } \\
\text { on Triton }\end{array}$ \\
\hline
\end{tabular}

("cryoclastic") volcanism, that were unobserved on the satellites of Jupiter and Saturn. It seemed that these features would be difficult to explain by eruptions of pure water, so that attention has since focussed on the chemically more complex aqueous solutions of ammonia and other volatiles (Stevenson 1982, Squyres et al. 1983, Croft and Soderblom 1991, Kargel et al. 1991, Schenk 1991, Kargel 1992, Croft et al. 1995). Alternatively, some of the thicker flows on the Uranian satellites have been explained by eruptions of warm, solid water ice or ice that was somewhat softened by inclusion of small amounts of methane or other volatiles (Jankowski and Squyres 1988). 
Although knowledge of the compositions of icy satellites and cryovolcanic deposits is rather poor, compositional variations of the first order are apparent from the densities of icy satellites, which indicate large differences in rock:ice ratios (Johnson et al., 1987). "Rock" may include silicate, metal sulfides, metallic iron-nickel, graphite, and other relatively dense and involatile phases, and "ices" may include water ice, ammonia hydrate, methane clathrate hydrate, nitrogen ice, and other highly volatile and lowdensity molecular ices. The average densities of a few satellites are very precisely known and the densities of others are roughly known from spacecraft radio tracking and observations of mutual gravitational perturbations. Most of the observed densities and rock:ice ratios fall within the range predicted by theoretical models of nebular condensation under different sets of assumed or modeled conditions. For example, condensation in a $\mathrm{CO}-\mathrm{N}_{2}$-rich nebula results in a larger rock:ice ratio than condensation in a $\mathrm{CH}_{4}-\mathrm{NH}_{3}$-rich nebula (Johnson et al. 1987, Prinn and Fegley 1988). Other processes can cause substantial volatile fractionations in the solar and circumplanetary nebulae, so that the variations in satellite densities or rock:ice ratios are unreliable indicators of nebular processes, conditions, and volatile assemblages; one may merely construct reasonable but nonunique models that fit the constraints. Regardless of exactly how the different rock:ice ratios arose, an important implication is that compositional variations in the volatile contents of icy satellites are also likely. Satellite densities are even less helpful with the volatile composition, because most of the predicted volatile ices have roughly comparable densities and cause similar effects on the bulk density of any mixture of rock and ices (Lewis 1972, Prinn and Fegley 1988).

\section{Possible compositions and properties of cryolavas}

Ubiquitous water ice features in the reflection spectra of all major icy satellites, except Triton, suggests that cryovolcanic flows are aqueous (Clark et al. 1986). The flows on Triton, too, are believed to be aqueous but covered by frosts of nonaqueous substances (mainly nitrogen with traces of other volatiles, Cruikshank et al. 1991, Croft et al. 1995). Triton is so distant from the sun, its surface so cold, and its mass so great that outgassed nitrogen and other molecular ices are retained as surfaces ices and in a tenuous atmosphere. However, Triton is warm enough and nitrogen and methane are volatile enough that any original volcanic flows of these substances probably would have long ago sublimed. Any substantial relief formed in frozen nitrogen by volcanic or tectonic activity would not only tend to sublimate but it would also tend to flow glacier-style very rapidly (even at Triton's frigid $38 \mathrm{~K}$ ) until sharp local relief disappeared (Croft $e t$ al. 1995). Hence, it is thought that Triton's substantial surface relief is formed in aqueous substances that are covered by nitrogen-rich frosts (Croft et al. 1994).

Titan possesses a dense atmosphere dominated by nonpolar gases (mainly nitrogen plus some methane, heavier hydrocarbons, and probably argon), although these gases cannot form stable solids on the surface (condensed liquid solutions may occur on Titan). The other icy satellites of Jupiter, Saturn, and Uranus are generally too warm for solid nitrogen and methane ices to exist, and these objects are generally too small to retain a substantial atmosphere; hence, most outgassed or extruded nitrogen and methane on the majority of icy satellites has probably been lost to space. Large amounts of gas clathrate hydrates may still be trapped in the satellites' interiors.

In sum, it is generally thought that cryovolcanic landscapes throughout the outer solar system are fundamentally aqueous. The general analogy between certain cryo- 
volcanic terrains, especially those on Triton, and silicate volcanic terrains on the rocky planets raises the intruiguing question of how aqueous solutions could have behaved much like silicate lavas so as to produce similar landforms. Multicomponent phase equilibria in the types of chemical systems indicated in Table 2 have helped in the identification of some likely aqueous lavas (Kargel 1991, 1992). Other laboratory measurements have shown that the rheological characteristics of solutions in the waterammonia-methanol series (a possible class of cryovolcanic lava) are comparable to the series of silicate lavas ranging from basalt to dacite (Kargel et al. 1991).

Laboratory studies have highlighted the volcanological importance of what may be minor constituents in bulk satellites but major constituents in multicomponent aqueous lavas. It is noteworthy that minor constituents in the Earth, such as $\mathrm{Na}, \mathrm{K}$, and $\mathrm{H}_{2} \mathrm{O}$, have petrologic and geologic importance disproportionate to their abundances $(0.25 \%, 0.02 \%$, and $\sim 0.03 \%$ of Earth's mass, respectively). For instance, these components are essential ingredients in the formation of granitoid rocks, and, thus, are keys to the origin of Earth's continental crust, to say nothing of the hydrosphere and biosphere. The importance of $\mathrm{Na}, \mathrm{K}$, and $\mathrm{H}_{2} \mathrm{O}$ to Earth's structure and geology is magnified because of the lithophile incompatible chemical nature of these components (i.e., they are concentrated in partial melts, and, thus, in Earth's crust). Likewise, minor water-soluble components of icy satellites, probably including many substances not mentioned in Tables 1-2, could be key ingredients in determining the many unique geologic histories, interior structures, and surface morphologies of icy satellites.

The space-filling characteristic of the plains on the Jovian and Saturnian satellites suggests that the flow substance(s) had a fairly low viscosity, perhaps like that of basaltic lava or something even less viscous (such as water, brine, or ammonia-water lacking large amounts of other chemical constituents or suspended crystals). By contrast, the cryovolcanic flows on the satellites of Uranus and Neptune are very thick and generally form lobate deposits and, on Triton, discrete volcanic constructs. This morphologic evidence suggests a profound rheological difference between the flows on the satellites of Jupiter/Saturn and those on the satellites of Uranus/Neptune. A simple accounting for this difference is that chemical variations caused flows to vary in viscosity (for example, due to different types of molecular bonding or different melting temperatures). The inferred rheological characteristics and the distribution of these two types of flows can be explained by the following working hypothesis.

(1) Flows on the Jovian and Saturnian satellites are thought to contain water and perhaps ammonia and salts, but not large quantities of other water-soluble substances (such as methanol) that would substantially further increase the liquids' viscosities.

(2) Flows on the Uranian and Neptunian satellites are thought to include, besides water, ammonia, and salts, large amounts of additional substances (such as methanol and/or hydrogen sulfide) that are highly soluble in low-temperature aqueous solutions and that would greatly increase the liquids' viscosities (Table 2) (Kargel et al. 1991).

These differences are consistent with the inclusion of a large amount of cometary or interstellar ices in the Uranian and Neptunian satellites, and the absence of a large fraction of such ices in the Jovian and Saturnian satellites. Cometary or interstellar components would introduce large amounts of clathrate hydrates, which would yield high-pressure aqueous liquids saturated in nonpolar gases (up to several weight percent); the gas-charged liquid would tend to devolatilize and cause explosive volcanism, consistent with extensive explosive cryovolcanism on Triton (Kargel and Strom 1990). An utter lack of any indication of explosive volcanism on Ganymede and Europa is strong evidence that nonpolar gases (in the form of clathrate hydrates) are virtually 
absent from the interior zones of these objects where partial melting occurred. Possible explosive volcanism on Enceladus sugests that it may be compositionally transitional somewhere between the satellites of Jupiter and those of Uranus and Neptune.

\section{References}

Burns, J.A. (1986) Some background about satellites, in J.A. Burns and M.S. Matthews (eds.), Satellites, University of Arizona Press, Tucson, pp. 1-38.

Clark, R.N., Fanale, F.P., and Gaffey, M.J. (1986) Surface composition of natural satellites, in J.A. Bums and M.S. Matthews (eds.), Satellites, University of Arizona Press, Tucson, pp. 437-491.

Consolmagno, G.J., and Lewis, J.S. (1978) The evolution of satellite interiors and surfaces, Icarus 34, 280293.

Croft, S.K. (1992), Proteus: Geology, shape, and catastrophic disruption, Icarus 99, 402-419.

Croft, S.K., and Soderblom, L.A. (1991) Geology of the Uranian satellites, in J.T. Bergstralh, E.D. Miner, and M.S. Matthews (eds.), Uranus, University of Arizona Press, Tucson, pp. 561-628.

Croft, S.K., Kargel, J.S., Kirk, R.L., Moore, J.M., Schenk, P.M., and Strom, R.G. (1995) The geology of Triton, in D.P. Cruikshank (ed.), Neptune and Triton, University of Arizona Press, Tucson (in press).

Cruikshank, D.P., et al. (1991) Tentative identification of $\mathrm{CO}$ and $\mathrm{CO}_{2}$ ices on Triton, Bull. Amer. Astronom. Soc. 23, 1208.

Ellsworth, K., and G. Schubert (1983) Saturn's icy satellites: Thermal and structural models, Icarus 54, 490510.

Farinella, P., Paolicchi, P., Strom, R.G., Kargel, J.S., and Zappalá, V. (1990) The fate of Hyperion's

fragments, Icarus 83, 186-204. .

Jankowski, D.G., and S.W. Squyres (1988) Solid-state ice volcanism on the satellites of Uranus, Science $241,1322$.

Johnson, T.V., R.H. Brown, and J.B. Pollack (1987) Uranus satellites: Densities and composition, $J$. Geophys. Res. 92, 14,884-14,894.

Kargel, J.S., and R.G. Strom (1990) Cryovolcanism on Triton, Lunar Planet. Sci. Conf. XXI, 599-600.

Kargel, J.S., 1991, Brine volcanism and the interior structures of asteroids and icy satellites, Icarus 94, 368390.

Kargel, J.S., S.K. Croft, J.I. Lunine, and J.S. Lewis (1991) Rheological properties of ammonia-water liquids and crystal-liquid slurries: Planetological applications, Icarus 89, 93-112.

Kargel, J.S. (1992) Ammonia-water volcanism on icy satellites: Phase relations at 1 atmosphere, Icarus $100,556-574$.

Kirk, R.L., Soderblom, L.A., Brown, R.H., Kieffer, S.W., and Kargel, J.K. (1995) Triton's plumes: Discovery, characteristics, and models, in D.P. Cruikshank (ed.), Neptune and Triton, The University of Arizona Press, Tucson (in press).

Lewis, J.S. (1971) Satellites of the outer planets: Their chemical and physical nature, Icarus 15, 174-185.

Lewis, J.S. (1972) Low-temperature condensation from the solar nebula, Icarus 16, 241-252.

Lucchitta, B.K., and Soderblom, L.A. (1982) The geology of Europa, in D. Morrison (ed.), Satellites of Jupiter, The University of Arizona Press, Tucson, pp. 521-555.

Prinn, R.G., and B. Fegley, Jr. (1988) Solar nebula chemistry: Origin of planetary, satellite, and cometary volatiles, in S.K. Atreya, J.B. Pollack, and M.S. Matthews (eds.), Planetary and Satellite Atmospheres: Origin and Evolution, University of Arizona Press, Tucson, pp. 78-136.

Rothery, D.A. (1992) Satellites of the Outer Planets: Worlds in Their Own Right, Oxford University Press, New York, pp. 208.

Schenk, P.M. (1990) Fluid volcanism on Ariel and Miranda: Flow morphology and composition, $J$. Geophys. Res. 96, 1887-1906.

Shoemaker, E.M., Lucchitta, B.K., Plescia, J.B., Squyres, S.W., and Wilhelms, D.E. (1982), The geology of Ganymede, in D. Morrison (ed.), Satellites of Jupiter, The University of Arizona Press, Tucson, pp. 435-520.

Smith, B.A., et al. (1979) The Jupiter system through the eyes of Voyager 1, Science 204, 951-972.

Smith, B.A., et al. (1982) A new look at the Saturn system: The Voyager 2 images, Science 215, 504-536.

Smith, B.A., et al. (1986) Voyager 2 in the Uranian system: Imaging science results, Science 233, 43-64.

Smith, B.A., et al. (1989) Voyager 2 at Neptune: Imaging science results, Science 246, 1422-1429.

Squyres, S.W., R.T. Reynolds, P.M. Cassen, and S.J. Peale (1983) The evolution of Enceladus, Icarus 53, 319-331.

Squyres, S.W., R.T. Reynolds, A.L. Summers, and F. Shung (1988) Accretional heating of the satellites of Saturn and Uranus, J. Geophys. Res. 93, 8779-8794.

Stevenson, D.J. (1982) Volcanism and igneous processes in small icy satellites, Nature 298, p. 142-144.

Strom, R.G. (1986) The solar system cratering record: Voyager 2 results at Uranus and implications for the origin of impacting objects, Icarus 70, 517-535.

Thomas, P.C. (1989) The shapes of small satellites, Icarus 77, 248-274. 